\title{
REVIEW
}

\section{Monocyte and Macrophage Plasticity in Tissue Repair and Regeneration}

\author{
Amitava Das, Mithun Sinha, Soma Datta, Motaz Abas, Scott Chaffee, Chandan K. Sen, and Sashwati Roy
}

From the Department of Surgery, Davis Heart and Lung Research Institute, Center for Regenerative Medicine and Cell Based Therapies and Comprehensive Wound Center, The Ohio State University Wexner Medical Center, Columbus, Ohio

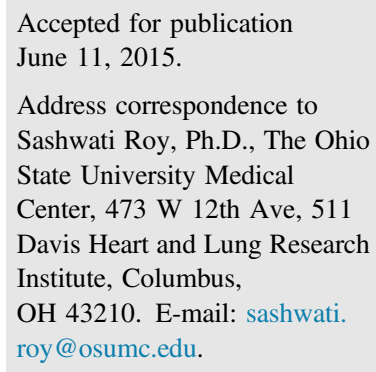

\begin{abstract}
Heterogeneity and high versatility are the characteristic features of the cells of monocyte-macrophage lineage. The mononuclear phagocyte system, derived from the bone marrow progenitor cells, is primarily composed of monocytes, macrophages, and dendritic cells. In regenerative tissues, a central role of monocyte-derived macrophages and paracrine factors secreted by these cells is indisputable. Macrophages are highly plastic cells. On the basis of environmental cues and molecular mediators, these cells differentiate to proinflammatory type I macrophage (M1) or anti-inflammatory or proreparative type II macrophage (M2) phenotypes and transdifferentiate into other cell types. Given a central role in tissue repair and regeneration, the review focuses on the heterogeneity of monocytes and macrophages with current known mechanisms of differentiation and plasticity, including microenvironmental cues and molecular mediators, such as noncoding RNAs. (Am J Pathol 2015, 185: 2596-2606; http://dx.doi.org/10.1016/j.ajpath.2015.06.001)
\end{abstract}

The concept of cell plasticity originated from the ability of adult stem cells to differentiate into multiple cell types. Heterogeneity and plasticity are the characteristic features of the cells of the monocyte-macrophage lineage. ${ }^{1}$ In response to the cues from local milieu, these cells have the ability to undergo phenotypic/ functional switch. In addition to switching between polarization states, these cells may transdifferentiate into endothelial or other cells in vitro and in vivo. In the current review, we focus on the heterogeneity and plasticity of monocytes and macrophages. The plasticity of macrophages plays a decisive role in tissue repair and regeneration. Herein, we discuss the current known mechanisms, including the roles of microenvironmental cues and molecular mediators, such as noncoding RNAs, underlying the plasticity and differentiation of macrophages in tissue repair and regeneration.

\section{Mononuclear Phagocyte System}

The mononuclear phagocyte system (MPS), originating from bone marrow progenitor cells, is composed of monocytes, macrophages, and dendritic cells (DCs), with phenotypic and functional overlaps between these cells. ${ }^{2}$ These cells differentiate and enter the systemic circulation to form monocytes, and then infiltrate into tissues to become macrophages. ${ }^{3}$ The other cells of the MPS (ie, DCs and macrophages) also have a remarkable heterogeneity related to their origin, phenotype, tissue localization, proliferative potential, and functions. ${ }^{1,4}$ Cells of MPS display plasticity in their gene expression patterns, thus identification based upon surface markers is often challenging. ${ }^{5}$ Activating the cells of the MPS by macrophage colony stimulating factor (MCSF)-1 and IL-34 results in proliferation as well as differentiation of these cells. ${ }^{6}$ The differentiation of DCs from hematopoietic stem and progenitor cells may occur inside extramedullary tissues. ${ }^{7}$

\section{Monocyte Origin, Function, and Heterogeneity}

Monocytes correspond to $10 \%$ or $4 \%$ of leukocytes in human or murine blood, respectively. In addition to playing a critical

\footnotetext{
Supported by National Institute of Diabetes and Digestive and Kidney Diseases grant R01 DK076566 (S.R.), National Institute of Nursing Research grants NR015676 (S.R.) and NR013898 and NR015676 (C.K.S.), and National Institute of General Medical Sciences grants RO1 GM108014, GM069589, and GM 077185 (C.K.S.).
}

A.D. and M.S. contributed equally to this work.

Disclosures: None declared.

This article is part of a review series on regenerative medicine. 


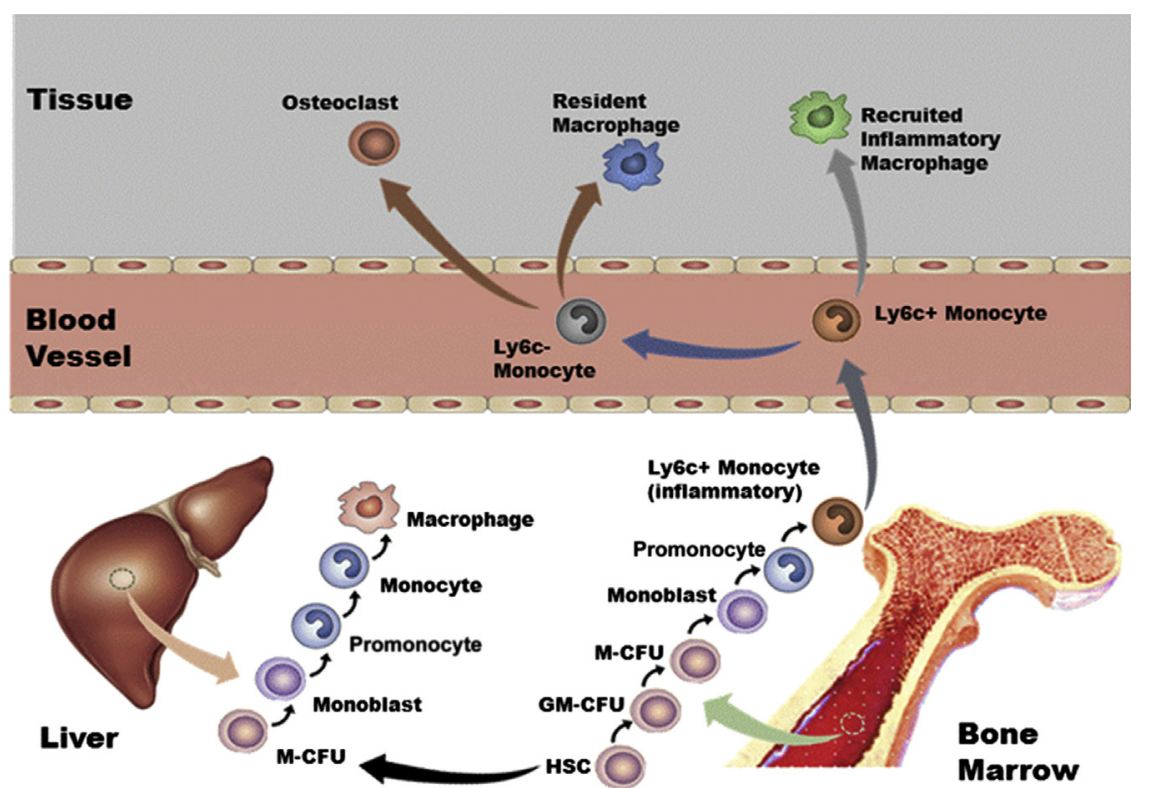

Figure 1 Origin and development of the mononuclear phagocyte system. Hematopoietic stem cells (HSCs) in fetal liver or adult bone marrow develop into a progenitor of both macrophages and granulocytes. The granulocyte-macrophage colonyforming unit (GM-CFU) population can commit to the macrophage colony-forming unit (M-CFU) or the granulocyte CFU group of cells. Before becoming macrophages, the M-CFU differentiates into monoblasts, promonocytes, and mature monocytes. This process requires the growth factor colonystimulating factor-1. In mice, Ly6C is a marker for an inflammatory population of monocytes. In humans, the corresponding marker is CD16. role in development, homeostasis, and inflammation, they are also responsible for the removal of apoptotic and necrotic cells. ${ }^{8}$ The monocytes originate from hematopoietic stem cell (HSC) monoblasts that differentiate to promonocytes and then to mature monocytes. (Figure 1). ${ }^{9}$ A clear understanding of monocyte heterogeneity is lacking, but it is suggested that monocytes mature in the blood and then get recruited to injury sites. The point at which these cells start their journey from blood may define their functions. ${ }^{10}$

In mice, two populations of monocytes have been identified and named as inflammatory and patrolling monocytes, depending on the time they spend in the blood before migrating to tissues. ${ }^{11}$ The Nomeclature Committee of the International Union of Immunologic Societies (Berlin, Germany) has recently approved a new nomenclature of monocytes in humans. According to this new system, the monocyte population has been divided into three subsets: i) the major, or classical, population of human monocytes (90\%) with high CD14 but no CD16 expression $\left(\mathrm{CD}^{+} 4^{+} \mathrm{CD} 16^{-}\right)$; ii) the intermediate subset $\left(\mathrm{CD} 14^{+} \mathrm{CD} 16^{+}\right)$, and iii) the low CD14- but high CD16expressing or nonclassical subset $\left(\mathrm{CD} 14^{\mathrm{dim}} \mathrm{CD} 16^{+}\right) .{ }^{12}$ Human classical and intermediate monocyte subsets that display inflammatory properties are referred to as inflammatory monocytes whereas the nonclassical monocyte subset demonstrates crawling or patrolling behavior along blood vessel walls. These cells are known to respond to viral infection. The plasticity of the inflammatory monocytes enables them to alter their phenotype based on the environment and/or the immune responses elicited after exposure to a particular pathogen. ${ }^{13}$

Although contentious, inflammatory monocytes have been reported to produce patrolling monocytes in the blood or bone marrow. ${ }^{13}$ A rare subset of monocytes is known to express TIE2, the receptor for angiopoietins, and is therefore termed TIE2-expressing monocytes. ${ }^{14}$ The TIE2-expressing monocytes and intermediate $\left(\mathrm{CD} 14^{+} \mathrm{CD} 16^{+}\right)$subsets of monocytes with high angiogenic potential have been associated with liver regeneration. ${ }^{14}$ Another example of involvement of monocytes in tissue regeneration is based on the observation that the osteoclasts of the regenerating salamander limb form by fusion of monocytes. ${ }^{15}$ These studies suggest involvement of specific subsets of monocytes in the tissue regeneration process.

\section{Origin, Function, and Heterogeneity}

DCs are essential mediators of innate and adaptive immune responses. ${ }^{16}$ The function and phenotypes of dendritic cells subsets remains to be elucidated. ${ }^{16}$ Relative to other cells of the MPS, our understanding of the molecular mechanisms that regulate the development of DCs is limited. DCs are composed of distinct subsets for which precise functions and interrelationships remain to be elucidated. The advances in establishing classic DCs as a distinct lineage among myeloid cells and their function in vivo have been recently reviewed. ${ }^{16}$ Because of relative rarity and phenotypic similarity to other cells of the MPS, their role in wound healing is not well described. Among DCs, the plasmacytoid DCs, which are normally not found in healthy skin, have been shown to rapidly infiltrate skin wounds with quick kinetics, similar to that of neutrophils. ${ }^{17}$ Whether such infiltration of plasmacytoid DCs into wounds is a general occurrence or is associated with conditions such as infection, remains to be tested. Plasmacytoid DCs, a rare population of circulating cells, produce high quantities of type I interferons (IFN) when exposed to viral infections. $^{18}$

\section{Macrophages}

Origin, Functions, and Steady-State Tissue Distribution

Considered to be important immune effector cells of the innate immune system, macrophages not only provide the 
Table 1 Tissue- and Organ-Specific Functions of Macrophages

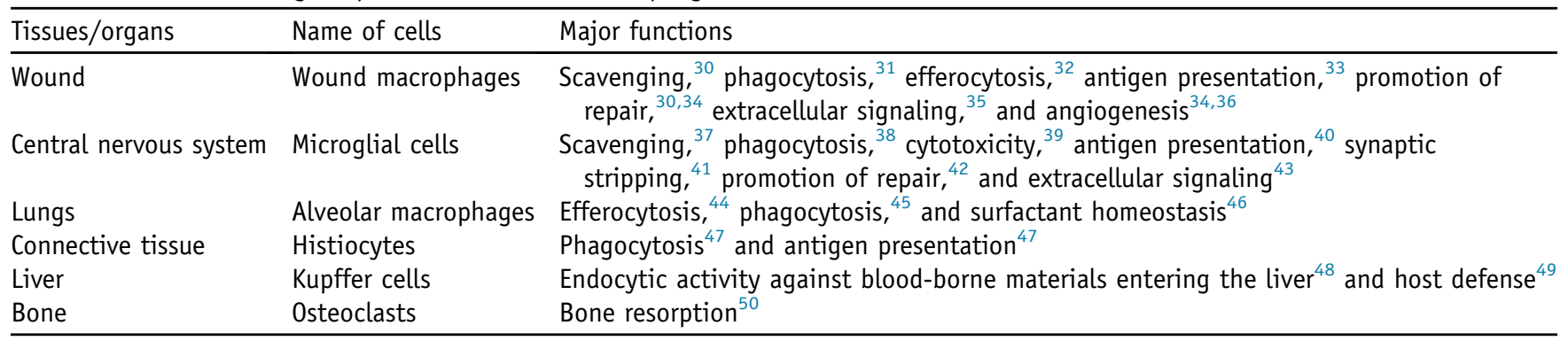

initial defense against microorganisms but also initiate and control the adaptive immune responses. ${ }^{19}$ Ilya Mechnikov, a Russian-French biologist, discovered in 1884 that certain white blood cells engulf and digest bacteria by a process that he referred to as phagocytosis, and the cells were named macrophages (derived from the Greek words makros, big, and phagein, to eat). ${ }^{20}$ Apart from being involved in producing required growth factors, macrophages are pivotal in tissue repair, remodeling, and synchronizing metabolic functions. $^{21,22}$ Macrophages efficiently clear apoptotic polymorphonuclear leukocytes, a prerequisite for a favorable resolution of inflammation, ${ }^{23}$ by efferocytosis (phagocytosis of apoptotic cells). ${ }^{24}$ A dysregulation in macrophage efferocytosis may lead to autoimmunity and persistent inflammatory diseases. ${ }^{25}$

Circulating blood monocytes were believed to be the exclusive precursors of tissue macrophages. ${ }^{26}$ Monocytes derived from the bone marrow differentiate to macrophages in the intestine and the dermis during acute infection and inflammation. ${ }^{27}$ However, reports indicate that macrophages in tissues like the liver and spleen originate from embryonic precursors derived from the yolk sac and self-replenish themselves. $^{28}$

Although macrophages in tissues have many features in common, they are nevertheless extremely heterogeneous in terms of function and surface marker expression ${ }^{29}$ (Table 1). ${ }^{30-50}$ The anatomical location of the macrophages dictates their heterogeneity in terms of their function. ${ }^{9}$ In the white adipose tissue, the number and the activation state of the macrophages determine the metabolic health of adipocytes, which, in turn, regulate the metabolism in the white adipose tissue through the release of hormones called adipokines. ${ }^{51,52}$ Macrophages present in the brown adipose tissue are required to enable the metabolic acclimatization to cold. ${ }^{53}$ The resident macrophages of the liver (alias Kupffer cells) comprise the largest section of tissue macrophages in the body ${ }^{54}$ that expedite the metabolic adaptations of hepatocytes during high caloric intake. ${ }^{53}$ Alveolar macrophages in the lungs phagocytose any potentially harmful pathogen that is taken in from the air during respiration. ${ }^{55}$ Interestingly, the cervical region consists of both proinflammatory type I macrophage (M1) and anti-inflammatory or propreparative type II macrophage (M2) phenotypes (discussed later), which are possibly responsible for the maternal tissue repair after birth. Increased presence of
M2 macrophages during labor and immediately after birth suggests a key role of M2 macrophages in maternal tissue repair after birth. ${ }^{56}$ Macrophages abundantly present in tumors are called tumor-associated macrophages (TAMs). ${ }^{57}$ Unlike the other tissue-resident macrophages, TAMs represent more of an M2 phenotype. ${ }^{57}$ M2-like TAMs in established tumors endorse tumor-induced immunosuppression, suggesting a switch of macrophage phenotype from M1 during tumor onset to M2 in established tumors. ${ }^{58-60}$

\section{Plasticity and Polarization}

Macrophages and their activation states are characterized by plasticity and flexibility. ${ }^{19,57,61}$ Depending on the environmental stimuli, macrophages have a wide array of functions, especially in the modulation of innate immune response through the release of several factors. ${ }^{62}$ In fact, some of these activities of macrophages are opposing. The diverse roles (ie, proinflammatory or anti-inflammatory nature of macrophages in immune responses) depend on the environmental stimuli that induce the macrophages to acquire a distinct functional phenotype. ${ }^{62}$ Although the microenvironmental stimuli and the phenotypes are diverse, macrophages have been primarily classified into two major phenotypes on the basis of the type 1 helper T-cell (Th1)/type 2 helper T-cell (Th2) polarization, according to the T-cell literature. ${ }^{9,30,57,63}$ As per the Th1/Th2 concept, cytokines such as IFN- $\gamma$ and tumor necrosis factor- $\alpha$ (TNF- $\alpha$ ), which are predominantly secreted by Th1 cells, activate macrophages to classically activated M1 macrophages. However, Th2 cytokines such as IL-4 and IL-10 have been found to inhibit macrophage activation, and these macrophages are referred to as anti-inflammatory M2 macrophages (Figure 2). ${ }^{64,65}$ Essential for early stages of tissue repair, M1 macrophages support pathogen killing and IL-12-mediated Th1 responses whereas reparative M2 macrophages support the effector functions of Th2 thymocytes and aid in the later stages of the repair process (Figure 3).

On the basis of the stimulus from the microenvironment, M2 macrophages are further subdivided into three subtypes: i) M2a is a profibrotic phenotype and is stimulated by IL-4 or $\mathrm{IL}-13,{ }^{66}$ ii) $\mathrm{M} 2 \mathrm{~b}$ is induced by combined exposure to immune complexes and Toll-like receptor or IL-1 receptor agonists, ${ }^{67}$ and iii) M2c is stimulated by IL-10, transforming growth factor (TGF)- $\beta$, or glucocorticoids and not only 


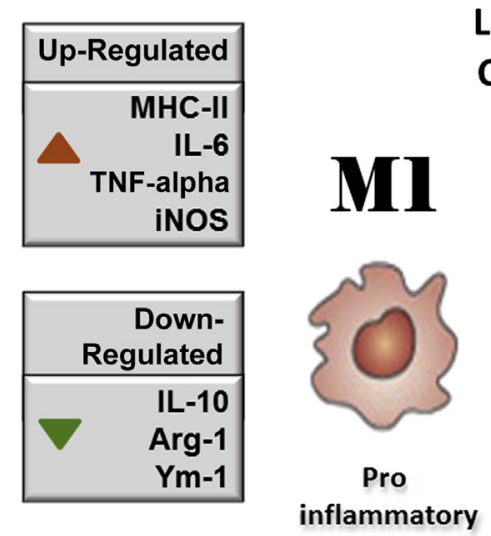

\section{Efferocytosis \\ Lipid Mediators, EPA DHA \\ Cell Signaling (JNK, PI3K,}

JAK-STAT)

Cytokines
miRNAs/IncRNAs
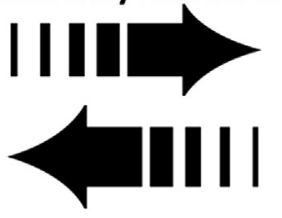

LPS, IL-21

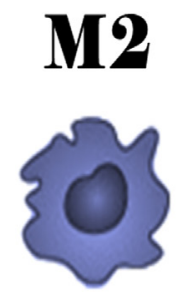

Anti-
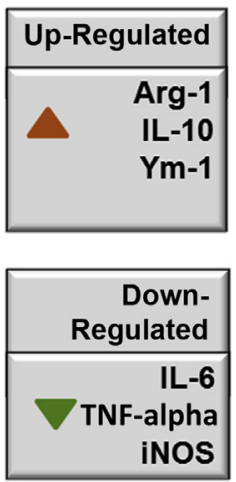

Figure 2 Macrophage polarization from a proinflammatory M1 to an anti-inflammatory M2 phenotype is mediated by a set of specific factors, including efferocytosis of apoptotic cells present at the site of inflammation, cytokines, lipid mediators, such as eicosapentaenoic acid (EPA) and docosahexaenoic acid (DHA), and cell signaling mediators c-Jun N-terminal kinase (JNK), janus kinase (JAK)-signal transducer and activator of transcription (STAT), and phosphatidylinositol 3-kinase (PI3K). The miRNAs and long noncoding RNAs (IncRNAs) also support macrophage polarization. The expressions of specific genes are altered in transition from M1 to M2. Up-regulated genes are shown with red arrowheads, whereas down-regulated genes are shown with green arrowheads. Arg-1, arginine-1; iNOS, inducible nitric oxide synthase; LPS, lipopolysachharide; MHC-II, major histocompatibility complex class II; TNF- $\alpha$, tumor necrosis factor $\alpha ; Y m-1$, chitinase 3-like 3.

causes suppression of inflammation but also promotes neovascularization. ${ }^{66}$ Microbicidal M1 macrophages utilize nitric oxide released by the increased levels of inducible nitric oxide synthase. ${ }^{68}$ Metabolism of arginine is rerouted by M2 macrophages to produce ornithine and polyamine, thereby fostering cell growth and leading to tissue repair. ${ }^{69}$ Macrophages are key players involved in the shift from the inflammatory to the proliferative phase, which decides the fate of the injury site. By releasing a wide array of growth factors and cytokines, macrophages recruit other cell types, such as fibroblasts, which, once activated, organize the new tissue matrix and promote angiogenesis. Macrophages are also known to modulate fibrosis and scarring during the reparative process of wound healing (Figure 3). ${ }^{70}$

\section{Wound Macrophages}

The macrophages that infiltrate the wounds are often referred to as wound macrophages. Studies performed to characterize wound macrophage phenotypes in our and other laboratories suggest that macrophage polarization state at the repair site is highly dynamic and is dependent on the wound environment. Therefore, at a given time, a continuum of macrophage polarization states is expected at the wound site. Mouse wound inflammation studies have suggested that, in early phase, the phenotype of wound macrophages partly displays features of the originator monocytes. These features changed with time to present a phenotype that did not correspond to the established classification system (ie, M1 or M2). ${ }^{71}$ Daley et al ${ }^{72}$ reported that wound macrophages share the characteristics of both classically and alternatively activated macrophages. The production of proinflammatory cytokines, such as TNF- $\alpha$ and IL-6, was more in day 1 wound macrophages, whereas day 7 wound macrophages produced more TGF- $\beta .^{72}$ The study also reported that, unlike the regulatory macrophages, wound macrophages did not release IL-10. ${ }^{72}$ This observation of IL-10 is contentious because studies from our laboratory clearly demonstrated production of IL-10 by wound macrophages, with a significant increase in the levels at a late phase of healing versus an early phase of wound healing. ${ }^{73}$ Our laboratory provided first evidence on the gene expression profile of wound macrophages extracted from chronic human wounds. ${ }^{74}$ Genome-wide screening for transcripts that were differentially expressed in chronic wound macrophages compared with blood monocyte-derived macrophages resulted in the identification of a focused set of 202 up-regulated and 49 down-regulated probe sets. These data suggest that wound macrophages have unique characteristics compared with cultured blood monocyte- $^{-}$derived macrophages. ${ }^{74}$

The paradigm of wound macrophages is unique and led to an interesting model of in vivo macrophage classification, which was proposed by Mosser and Edwards. ${ }^{19}$ According to this classification, instead of phenotypic markers, macrophages are classified on the basis of functions - host defense, wound healing, and immune regulation. ${ }^{19}$ This method is helpful because instead of two groups of macrophages, this concept provides a continuum of macrophage population on the basis of their function. The approach of classification of Mosser and Edwards ${ }^{19}$ is helpful in accommodating the macrophages that share the phenotypes of both populations, such as in wound healing. As per current literature, the macrophage polarization states have been defined using multiple terminologies such as M1 or classical and M2 or alternative. These terminologies are often contentious and confusing. ${ }^{75}$ To establish a uniform nomenclature system for macrophage activation states, a novel system based on source, activators, and markers associated with macrophage activation has been proposed. ${ }^{75}$ 


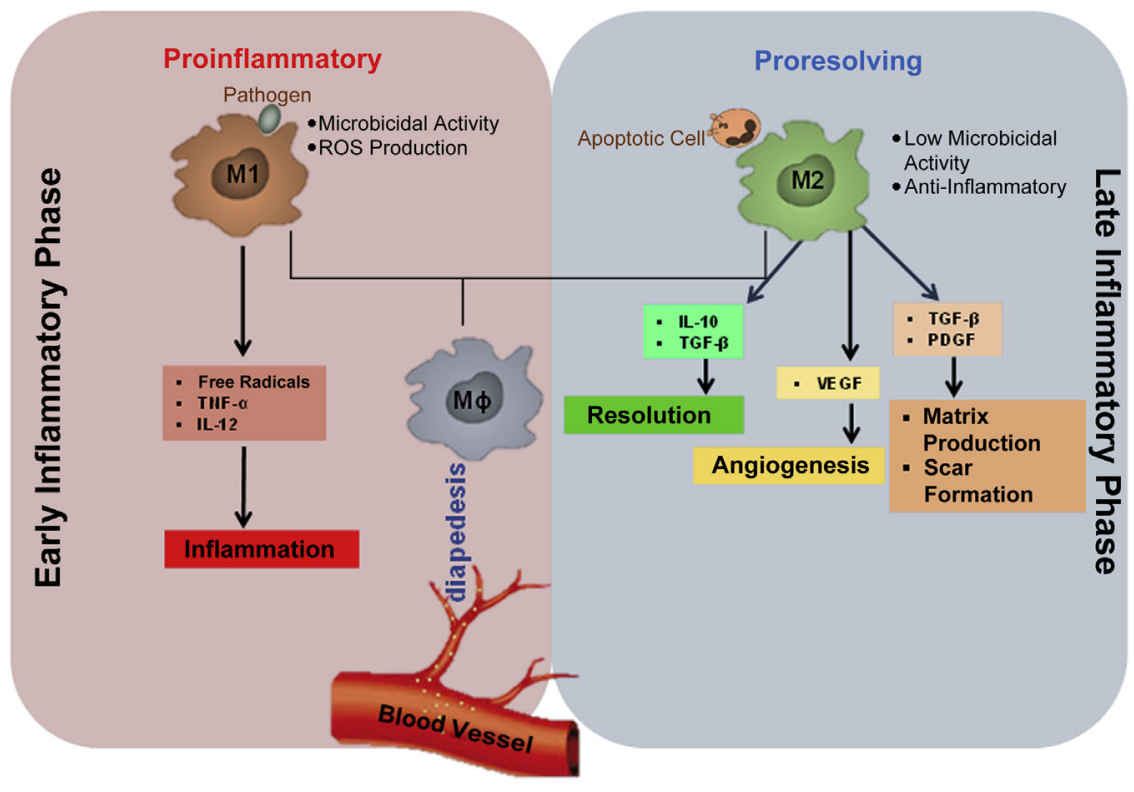

Figure 3 Macrophage plasticity in tissue repair. After injury, the macrophage $(M \phi)$ arrives at the site of injury from the systemic circulation via diapedesis. In the early phase, the inflammatory milieu drives macrophage toward M1 polarization. M1 macrophages possess potent microbicidal properties and support IL-12-mediated type 1 helper T-cell responses, which are essential in the early stages of wound healing. In the late inflammatory phase, the change in wound microenvironment and the process of efferocytosis (clearance of apoptotic cells) drive the M1 macrophages toward M2 polarization. M2 supports type 2 helper T-cell-related effector functions and plays a more reparative role in the later stages of wound healing. Macrophages play a major role in the transition of the wounds from the inflammatory to the resolution or proliferative phase, driving angiogenesis and matrix production. PDGF, platelet-derived growth factor; TGF, transforming growth factor; TNF, tumor necrosis factor; VEGF, vascular endothelial growth factor.

\section{Can Macrophages Switch Polarization State?}

It is contentious whether the alternatively activated reparative macrophages that are predominant at an injury site during the repair phase are derived from a subset of entirely newly recruited monocytes or result from M1 macrophages switching their phenotype. ${ }^{73}$ There are three major hypotheses attempting to explain the phenomenon. ${ }^{12}$ Specific subsets of monocytes can assume a specific phenotype. For example, Ly $6 \mathrm{C}^{+}$monocytes become $\mathrm{M} 1$ macrophages, and Ly6 $\mathrm{C}^{-}$monocytes become M2 macrophages. However, the observations that $\mathrm{Ly}^{-} \mathrm{C}^{-}$cells differentiate to $\mathrm{M} 1$ and Ly6C ${ }^{+}$cells to $\mathrm{M} 2{ }^{12}$ as well as differentiation of M1 to $\mathrm{M} 2^{23,76}$ weaken this argument. The second view proposes that monocytes are recruited as waves into a tissue during inflammatory response. Monocytes recruited into the tissue at different times come across different microenvironmental signals that can polarize them into specific phenotypes, depending on early versus late inflammatory phase. The observation that M2 macrophages derive largely from M1 macrophages ${ }^{23,76}$ does not support the second view as well. The third view suggests that, depending on environmental cues, macrophages can differentiate from an $\mathrm{M} 1$ to an M2 phenotype. Porcheray et $\mathrm{al}^{76}$ investigated whether the same macrophage population involved in inflammatory response switches to a more reparative phenotype in the later phase of healing. It was clearly demonstrated that the activation state of the macrophages was rapidly and fully reversible, suggesting that a given cell may participate sequentially in both the induction and the resolution of inflammation. ${ }^{76}$ Studies from our laboratory also support the third view. We have demonstrated that successful efferocytosis and molecular mediators, such as miR-21, switch macrophages to an antiinflammatory phenotype that helps in the resolution of inflammation. ${ }^{23,73}$ Such switching from a proinflammatory to an anti-inflammatory phenotype was facilitated by modifying intracellular noncoding miRNA, miR-21 or miR21 target proteins phosphatase and tensin homolog (PTEN) and programmed cell death 4 (PDCD4) levels. ${ }^{23}$ Earlier, we had demonstrated that under conditions of diabetes, a dysfunction in efferocytosis, forces wound macrophages to remain in a proinflammatory (M1) phase. ${ }^{73}$

The conversion of proinflammatory M1 macrophages to anti-inflammatory M2 macrophages is beneficial in circumstances where resolution of inflammation is required, as in wound healing. However, in cancer, macrophages tend to harbor more of an anti-inflammatory M2 phenotype, where conversion to an M1 phenotype might aid in removal of cancer cells. Lipopolysaccharide (LPS) has been reported to induce an M1 phenotype from an M2 phenotype. $^{77}$ Furthermore, tumor-mediated M2-like macrophages can be reprogrammed to M1-like cells by activation of CD40 using IFN $-\gamma{ }^{78}$ Furthermore, reports have indicated that when fully polarized M2 macrophages present antigen to Th1 cells in a tumor milieu, this interaction results in repolarization of M2 to M1 macrophages. ${ }^{79}$

\section{Metabolic Reprogramming in Macrophage Plasticity}

An excellent review recently highlighted the significance of metabolic state in macrophage plasticity. ${ }^{69}$ Tracer-based studies using $\left[1,2-{ }^{13} \mathrm{C}_{2}\right]$ glucose suggest that activated macrophages are glycolytic cells and that the metabolic pathway clearly differs in M1 and M2 subsets. ${ }^{80}$ In M1 macrophages, upon activation, aerobic glycolysis is induced, resulting in increased glucose uptake. Concomitantly, the induction of a pentose phosphate pathway occurs. The pentose phosphate pathway provides NADPH for the production of reactive oxygen species (ROS) and attenuation in mitochondrial respiratory change, resulting in augmented ROS production. 
M2 macrophages, on the other hand, use fatty acid oxidation. Inducing oxidative metabolism can switch M1 macrophages to an M2 phenotype. ${ }^{69}$ Activation of phosphofructokinase 2 isoenzymes acts as a switch between differential metabolic states of M1 and M2 macrophages. ${ }^{80}$ The dissimilarities in the metabolic states of M1 and M2 are well accepted. However, the underlying mechanisms involved in switching between metabolic states are not well understood. ${ }^{69}$

\section{Mechanisms of Macrophage Polarization and Plasticity}

Macrophages respond to environmental cues (eg, microbial products, damaged cells, and activated lymphocytes) with the acquisition of distinct functional phenotypes. Macrophage plasticity is extended to other cell types too, because they have been shown to transdifferentiate to endothelial cells. ${ }^{81,82}$ Transcriptional regulation of macrophage polarization (signal transducer and activator of transcription, interferon regulatory factor, and peroxisome proliferator-activated receptor $\gamma$ ) in activation of M1 or M2 polarization has been comprehensively reviewed. ${ }^{83}$ This review, therefore, has been limited to discussion on novel mechanistic underpinning of polarization. Among other regulators, phospholipase $C \beta 2$, responsible for catalyzing the formation of inositol 1,4,5-trisphosphate and diacylglycerol from phosphatidylinositol 4,5-bisphosphate, has been implicated in switching of macrophages from M1 to M2 phenotype. ${ }^{84}$ Macrophages lacking src homology 2-containing inositol phosphatase exhibit elevated phosphatidylinositol $(3,4,5)$ trisphosphate levels, which switch nitric oxide-producing M1 macrophages to reparative M2 macrophages, suggesting that src homology 2-containing inositol phosphatase suppresses the production of M2 macrophages. ${ }^{85}$

\section{Cell Signaling Mediators}

The cAMP response element-binding protein is a crucial transcription factor for up-regulating IL-10 and arginine-1, which are associated with the M2 phenotype, and repressing M1 activation. Deletion of two cAMP response element-binding protein binding sites from the CCAAT/ enhancer-binding protein $\beta(\mathrm{C} / \mathrm{EBP} \beta)$ gene promoter blocks the downstream induction of anti-inflammatory genes associated with M2-like macrophage activation. Mice carrying the mutated C/EBP $\beta$ promoter, upon muscular injury, efficiently clear injured muscle from necrotic debris, but display severe defects in muscle fiber regeneration. This confirms the persistence of inflammatory macrophages in damaged muscles of these mice. ${ }^{86}$ Interestingly, increased AMP protein kinase activity has been associated with a decreased proinflammatory status of macrophages. ${ }^{87}$ Indeed, AMP protein kinase $\alpha 1$ knockout macrophages fail to adopt an anti-inflammatory (M2) phenotype and display a defect in the phagocytic activity. ${ }^{88}$
In skeletal muscle wounds, mitogen-activated protein kinase phosphatase (MKP)-1 facilitates transition from M1 to M2 phenotype ${ }^{89}$ Gene-expression analyses on $M K P-1^{-1-}$ muscle macrophages indicate that MKP-1 controls the inflammatory response and the switch from early proinflammatory to late antiinflammatory macrophage phenotype via p38 mitogenactivated protein kinase down-regulation. Mice deficient in MKP-1 display defective muscle regeneration with persistence of damage and impaired growth of regenerating myofibers. The wild-type phenotype is restored by $M K P-1^{+/+}$bone-marrow transplantation. ${ }^{89}$

A key molecule of signal transduction pathway Akt also contributes to macrophage polarization, depending on its isoform. Akt1 ablation in macrophages produces an M1 macrophage phenotype, and Akt2 ablation results in an M2 phenotype. ${ }^{90} \mathrm{Akt}^{-1-}$ mice are more resistant to LPS-induced endotoxin shock and to dextran sulfate sodium-induced colitis than wild-type mice, whereas Akt1 ablation renders the mice more sensitive to LPS-induced endotoxin shock. ${ }^{90}$

Furthermore, it has been shown that recepteur d'origine nantais (RON) receptor tyrosine kinase drives macrophage polarization to M2. RON knockout mice are sensitive to LPS challenge. ${ }^{91}$ RON signaling decreases proinflammatory cytokine production, suppresses nitric oxide synthase, and, at the same time, up-regulates arginase. ${ }^{92}$

The presence of macrophages at a wound site in the early phase of healing, characterized by low oxygen levels, ${ }^{93}$ suggests a role of hypoxia in macrophage phenotype and function. Indeed, the transcription factor hypoxia-inducible factor (HIF) plays a critical role in the adaptation of macrophages at the injury site. ${ }^{69}$ HIF $1 \alpha$ and HIF2 $\alpha$ have been implicated in M1 and M2 phenotypes, respectively. Such differential roles of HIF isoforms in macrophage polarization at the wound site are not clearly understood yet. ${ }^{69}$

\section{miRNA and Long Noncoding RNAs}

miRNAs are short noncoding RNAs of approximately 21 to 23 nucleotides in length. The database of miRNAs, miRBase, enlists 30,424 mature miRNA sequences across different species (miRBase; University of Manchester, Manchester, UK; $h t t p: / / w w w . m i r b a s e . o r g$, database version 20). miRNAs are primarily involved in post-transcriptional silencing of genes. They bind to the target mRNA transcripts leading to translational repression or degradation of mRNA transcripts. This pairing between miRNA and mRNA is usually of partial complementarity, resulting in a single miRNA targeting numerous mRNA transcripts. A single miRNA, on average, is predicted to target approximately 200 mRNA transcripts. ${ }^{94}$ What makes this regulatory network even more interesting is the observation that a single mRNA is targeted by more than one miRNA, depending on the length of the $3^{\prime}$-untranslated region of the mRNA. Recent studies, including those in our laboratory, emphasize the role played by miRNAs in regulating macrophage plasticity. 
The miRNA let-7c promotes M2 macrophage polarization and suppresses M1 polarization. ${ }^{95}$ The let-7c down-regulates C/EBP- $\delta$, an important transcriptional factor that is required for a sustained Toll-like receptor 4-induced inflammatory response, which promotes the M1 phenotype ${ }^{95,96}$ Similar to the role of let-7c, miR-124 diminishes M1 polarization and enhances M2 polarization in bone marrow-derived macrophages from mice. Overexpression of miR-124 reduces expression of the surface markers CD45, CD11b, F4/80, major histocompatibility complex class II, and CD86, but increases the expression of the M2 phenotypic markers found in inflammatory zone 1 (FIZZ1) and arginine-1. In contrast, knockdown of miR-124 enhances the expression of the surface markers CD45 and major histocompatibility complex class II in bone marrow-derived macrophages. ${ }^{97}$

C/EBP- $\alpha$ was identified as the mediator of the effect of miR124 on macrophage polarization. Such as let-7c and miR-124, miR-223 promotes the M2 fate. miR-223 is induced upon LPS treatment but is down-regulated when treated with IL-4. ${ }^{98}$ miR-223-deficient macrophages were hypersensitive to LPS stimulation, whereas such macrophages exhibited delayed responses to IL-4 compared with controls. ${ }^{98}$ The polarization was mediated via Pknox1, a proinflammatory gene that was identified in these studies as a target of miR-223. Our group has reported that miR-21 enables efficient resolution of inflammation in postefferocytosis macrophages. We speculate that such resolution of inflammation will drive macrophages toward the M2 phenotype via PTEN-NF- $\mathrm{B}$ and PDCD4-activator protein 1 pathways. ${ }^{23}$

Apart from small noncoding RNAs, long noncoding RNAs (lncRNAs) are also emerging as factors that might influence macrophage plasticity. Although direct evidence of lncRNAs in determining macrophage fate is lacking, their influence on the process cannot be ruled out on the basis of upcoming reports. IncRNA E330013P06 overexpression in macrophages induced proinflammatory genes and enhanced responses to inflammatory signals. ${ }^{99}$ Similarly, studies with linc1992 demonstrated that this lncRNA forms a heterogeneous nuclear ribonucleoprotein $\mathrm{L}$ that may regulate transcription of the TNF- $\alpha$ gene by binding to its promoter. Knockdown of linc1992 caused dysregulation of TNF- $\alpha$ during innate activation of human leukemic cell line macrophages. ${ }^{100}$

\section{Lipid Mediators}

The role of lipid and lipoprotein molecules adds a novel element to the regulation of macrophage polarization. Oxidized lowdensity lipoprotein regulates the gene expression profile of M1 and M2 macrophages derived from cultured human monocytes. ${ }^{101}$ Molecular network analysis showed that most of the molecules in the oxidized low-density lipoprotein-induced M1 macrophages are directly or indirectly related to TGF- $\beta 1 .{ }^{101}$ Furthermore, it has been well documented that chemical mediators biosynthesized from arachidonic acid, which include prostaglandins and leukotriene B4, are involved in the activation of the initial phase of diapedesis. ${ }^{102,103}$ Lipid molecules derived from $\omega-3$ polyunsaturated fatty acid substrates play multiple roles, including stimulation of macrophage efferocytosis, IL-10 production, and resolution of inflammation. Resolvin E1, an eicosapentaenoic acid family member, promotes phagocytosis at concentrations as low as $1 \mathrm{nmol} / \mathrm{L}$. In addition, the NADPH oxidase mediated ROS generation and IL-10 production was induced. ${ }^{104}$ Maresin derived from docosahexaenoic acid acts as a switch from M1 to M2 transition. ${ }^{105}$

\section{Macrophage Plasticity}

\section{Transdifferentiation}

The major goal of tissue regeneration is to replace the injured tissue to near original. Transdifferentiation (ie, switch to another cell type) and reprogramming (ie, induction to become pluripotent cells) are critical processes of the regenerative process. Herein, we describe the significance of these processes in the context of macrophage plasticity. The ability of macrophages to transdifferentiate into endothelial cells, endothelial progenitor cells, or endothelial-like cells both in vitro and in vivo has been documented. ${ }^{106,107}$ The generation of endothelial progenitor cells from macrophages is crucial given the fact that this aspect of macrophage plasticity could be used to stimulate the revascularization of injured blood vessels in ischemic tissues. Macrophages have also been shown to infiltrate the corneal stroma and transdifferentiate into lymphatic endothelial cells. ${ }^{108}$ By overexpression of vascular endothelial growth factor, macrophages can be stimulated to transdifferentiate to the endothelial cell type. ${ }^{106}$ Pleiotrophin (PTN) expressed by macrophages under ischemic conditions can promote transdifferentiation of macrophages to endothelial cells both in vitro and in vivo. PTN-induced transdifferentiation of macrophages has been shown to be regulated at the transcription level by GATA-2 and GATA-3. ${ }^{109}$ Transdifferentiation of macrophage to other cell lineages, thus, cannot be ruled out, and reports in this direction will help us to understand macrophage plasticity more vividly.

\section{Reprogramming}

Although studies related to functional plasticity of macrophages are still in early stages, work has been performed to alter macrophage fate in vivo at desired sites. Discussed in the previous section, PTN can induce transdifferentiation of macrophage to endothelial cells. The authors demonstrated that under in vivo conditions in mice, the monocytic cells that express PTN get integrated into blood vessels. ${ }^{109}$ Tumor-infiltrating macrophages and TAMs have been described as suppressor macrophages that display anti-inflammatory and immunosuppressive activities. ${ }^{110,111}$ In vivo delivery of IL-12 to tumor sites results in the conversion of tumor-infiltrating macrophages and TAMs from the anti-inflammatory phenotype to the proinflammatory phenotype. $^{112}$ IL-12-treated macrophages secrete IL-15, 
demonstrating their anti-inflammatory nature. IL-12 treatment could alter the function of these tumor-associated suppressor macrophages, reducing tumor supportive macrophage activities. Analysis of tumor-infiltrating macrophages and distal TAMs revealed that IL-12, both in vivo and in vitro, induced a rapid reduction of tumor-supportive macrophage activities (IL10 , monocyte chemoattractant protein-1, migration inhibitory factor, and TGF- $\beta$ production) and a concomitant increase in proinflammatory and proimmunogenic activities. ${ }^{112}$

Macrophages are traditionally known to be derived from myeloid cells. However, it has been recently shown that induced pluripotent cells (iPSCs) can also produce functional macrophages, ${ }^{113}$ as shown by the generation of human iPS cell clones by lentivirus-mediated transfer of Yamanaka factor (Oct3/4, Sox2, c-Myc, and Klf4) transgenes into dermal fibroblasts, followed by treatment with granulocyte-macrophage CSF, macrophage CSF, and IL-4. Although iPSCs can produce macrophages, the functionality of the macrophage will be dependent on the source of iPSC. The evidence was provided by Jiang et al, ${ }^{114}$ who studied patients experiencing chronic granulomatous disease, an inherited disorder of macrophages in which NADPH oxidase is defective in generating ROS. In CGD patients, macrophages derived from iPSCs retain their phagocytic function but suffer from compromised ROS production. ${ }^{114}$ This evidence also supported the notion that macrophages originating from iPSCs behave similar to those originating from myeloid cells.

\section{Perspectives}

Monocytes and macrophages are versatile and plastic cells, and the function and phenotype of these cells are regulated by the signals from the local milieu. Macrophages may assume multiple phenotypes, depending on conditions at the region of interest. Therefore, the polarization of macrophages should be considered as a spectrum, of which the classical and alternative activation states represent two extremes in the state of macrophage polarization. The local environment of a tissue repair site is highly dynamic and responsive to the progressive healing or futile nonhealing outcomes. Thus, at the site of tissue injury, macrophages may exist at any one point in the continuum of macrophage polarization states. In addition, monocytes may transdifferentiate to several cell types influencing the fate of tissue repair. Current evidence in this direction is scanty but lays the foundation to warrant further investigation. Given the versatility of monocytes and macrophages at the site of tissue injury, together with their profound influence on repair outcomes, it will be of substantial therapeutic value to gain traction on interventions aimed at tuning macrophage fate at the site of tissue injury.

\section{References}

1. Sica A, Mantovani A: Macrophage plasticity and polarization: in vivo veritas. J Clin Invest 2012, 122:787-795
2. Strauss O, Rod Dunbar P, Bartlett A, Phillips A: The immunophenotype of the antigen presenting cells of the mononuclear phagocyte system in the normal human liver: a systematic review. J Hepatol 2015, 62:458-468

3. Hume DA, Ross IL, Himes SR, Sasmono RT, Wells CA, Ravasi T: The mononuclear phagocyte system revisited. J Leukoc Biol 2002, 72:621-627

4. Taylor PR, Gordon S: Monocyte heterogeneity and innate immunity. Immunity 2003, 19:2-4

5. Hume DA: Differentiation and heterogeneity in the mononuclear phagocyte system. Mucosal Immunol 2008, 1:432-441

6. Hume DA, MacDonald KP: Therapeutic applications of macrophage colony-stimulating factor-1 (CSF-1) and antagonists of CSF-1 receptor (CSF-1R) signaling. Blood 2012, 119:1810-1820

7. Massberg S, Schaerli P, Knezevic-Maramica I, Kollnberger M, Tubo N, Moseman EA, Huff IV, Junt T, Wagers AJ, Mazo IB, von Andrian UH: Immunosurveillance by hematopoietic progenitor cells trafficking through blood, lymph, and peripheral tissues. Cell 2007, 131:994-1008

8. Serbina NV, Jia T, Hohl TM, Pamer EG: Monocyte-mediated defense against microbial pathogens. Annu Rev Immunol 2008, 26:421-452

9. Gordon S, Taylor PR: Monocyte and macrophage heterogeneity. Nat Rev Immunol 2005, 5:953-964

10. Sunderkotter C, Nikolic T, Dillon MJ, Van Rooijen N, Stehling M, Drevets DA, Leenen PJ: Subpopulations of mouse blood monocytes differ in maturation stage and inflammatory response. J Immunol 2004, 172:4410-4417

11. Geissmann F, Jung S, Littman DR: Blood monocytes consist of two principal subsets with distinct migratory properties. Immunity 2003, $19: 71-82$

12. Italiani P, Boraschi D: From monocytes to M1/M2 macrophages: phenotypical vs. functional differentiation. Front Immunol 2014, 5: 514

13. Mitchell AJ, Roediger B, Weninger W: Monocyte homeostasis and the plasticity of inflammatory monocytes. Cell Immunol 2014, 291:22-31

14. Schauer D, Starlinger $P$, Zajc P, Alidzanovic L, Maier T, Buchberger E, Pop L, Gruenberger B, Gruenberger T, Brostjan C: Monocytes with angiogenic potential are selectively induced by liver resection and accumulate near the site of liver regeneration. BMC Immunol 2014, 15:50

15. Fischman DA, Hay ED: Origin of osteoclasts from mononuclear leucocytes in regenerating newt limbs. Anat Rec 1962, 143:329-337

16. Satpathy AT, Wu X, Albring JC, Murphy KM: Re(de)fining the dendritic cell lineage. Nat Immunol 2012, 13:1145-1154

17. Gregorio J, Meller S, Conrad C, Di Nardo A, Homey B, Lauerma A, Arai N, Gallo RL, Digiovanni J, Gilliet M: Plasmacytoid dendritic cells sense skin injury and promote wound healing through type I interferons. J Exp Med 2010, 207:2921-2930

18. Cella M, Jarrossay D, Facchetti F, Alebardi O, Nakajima H, Lanzavecchia A, Colonna M: Plasmacytoid monocytes migrate to inflamed lymph nodes and produce large amounts of type I interferon. Nat Med 1999, 5:919-923

19. Mosser DM, Edwards JP: Exploring the full spectrum of macrophage activation. Nat Rev Immunol 2008, 8:958-969

20. Zalkind S: Ilya Mechnikov: His Life and Work. Honolulu, HI, University Press of the Pacific, 2001, pp 212

21. Geissmann F, Manz MG, Jung S, Sieweke MH, Merad M, Ley K: Development of monocytes, macrophages, and dendritic cells. Science 2010, 327:656-661

22. Gordon S, Martinez FO: Alternative activation of macrophages: mechanism and functions. Immunity 2010, 32:593-604

23. Das A, Ganesh K, Khanna S, Sen CK, Roy S: Engulfment of apoptotic cells by macrophages: a role of microRNA-21 in the resolution of wound inflammation. J Immunol 2014, 192:1120-1129

24. Gardai SJ, Bratton DL, Ogden CA, Henson PM: Recognition ligands on apoptotic cells: a perspective. J Leukoc Biol 2006, 79: 896-903 
25. Tibrewal N, Wu Y, D’Mello V, Akakura R, George TC, Varnum B, Birge RB: Autophosphorylation docking site Tyr-867 in Mer receptor tyrosine kinase allows for dissociation of multiple signaling pathways for phagocytosis of apoptotic cells and down-modulation of lipopolysaccharide-inducible NF-kappaB transcriptional activation. J Biol Chem 2008, 283:3618-3627

26. van Furth R, Cohn ZA: The origin and kinetics of mononuclear phagocytes. J Exp Med 1968, 128:415-435

27. Jakubzick C, Gautier EL, Gibbings SL, Sojka DK, Schlitzer A, Johnson TE, Ivanov S, Duan Q, Bala S, Condon T, van Rooijen N, Grainger JR, Belkaid Y, Ma'ayan A, Riches DW, Yokoyama WM, Ginhoux F, Henson PM, Randolph GJ: Minimal differentiation of classical monocytes as they survey steady-state tissues and transport antigen to lymph nodes. Immunity 2013, 39:599-610

28. Yona S, Kim KW, Wolf Y, Mildner A, Varol D, Breker M, StraussAyali D, Viukov S, Guilliams M, Misharin A, Hume DA, Perlman H, Malissen B, Zelzer E, Jung S: Fate mapping reveals origins and dynamics of monocytes and tissue macrophages under homeostasis. Immunity 2013, 38:79-91

29. Ovchinnikov DA: Macrophages in the embryo and beyond: much more than just giant phagocytes. Genesis 2008, 46:447-462

30. Gordon S: Alternative activation of macrophages. Nat Rev Immunol 2003, 3:23-35

31. Gigli I, Nelson RA Jr: Complement dependent immune phagocytosis, I: requirements for C'1, C'4, C'2, C'3. Exp Cell Res 1968, 51:45-67

32. Henson PM, Bratton DL, Fadok VA: Apoptotic cell removal. Curr Biol 2001, 11:R795-R805

33. Roy S, Sen CK. Inflammation: A hallmark of obesity in conflict with wound healing. Obesity: Epidemiology, Pathophysiology, and Prevention, 2nd Edition. Edited by Bagchi D, Pruess HG. Boca Raton, FL, CRC Press, 2013

34. Leibovich SJ, Ross R: The role of the macrophage in wound repair: a study with hydrocortisone and antimacrophage serum. Am J Pathol 1975, 78:71-100

35. Ferrante CJ, Leibovich SJ: Regulation of macrophage polarization and wound healing. Adv Wound Care (New Rochelle) 2012, 1:10-16

36. Sunderkotter C, Steinbrink K, Goebeler M, Bhardwaj R, Sorg C: Macrophages and angiogenesis. J Leukoc Biol 1994, 55:410-422

37. El Khoury J, Hickman SE, Thomas CA, Cao L, Silverstein SC, Loike JD: Scavenger receptor-mediated adhesion of microglia to beta-amyloid fibrils. Nature 1996, 382:716-719

38. Hanisch UK, Kettenmann H: Microglia: active sensor and versatile effector cells in the normal and pathologic brain. Nat Neurosci 2007, 10: 1387-1394

39. Ferrari D, Chiozzi P, Falzoni S, Dal Susino M, Collo G, Buell G, Di Virgilio F: ATP-mediated cytotoxicity in microglial cells. Neuropharmacology 1997, 36:1295-1301

40. Aloisi F: Immune function of microglia. Glia 2001, 36:165-179

41. Blinzinger K, Kreutzberg G: Displacement of synaptic terminals from regenerating motoneurons by microglial cells. Z Zellforsch Mikrosk Anat 1968, 85:145-157

42. Minghetti L, Levi G: Microglia as effector cells in brain damage and repair: focus on prostanoids and nitric oxide. Prog Neurobiol 1998, 54 : 99-125

43. Marchand F, Perretti M, McMahon SB: Role of the immune system in chronic pain. Nat Rev Neurosci 2005, 6:521-532

44. Schagat TL, Wofford JA, Wright JR: Surfactant protein A enhances alveolar macrophage phagocytosis of apoptotic neutrophils. J Immunol 2001, 166:2727-2733

45. Sibille Y, Reynolds HY: Macrophages and polymorphonuclear neutrophils in lung defense and injury. Am Rev Respir Dis 1990, $141: 471-501$

46. Weaver TE, Whitsett JA: Function and regulation of expression of pulmonary surfactant-associated proteins. Biochem J 1991, 273(Pt 2): 249-264

47. Cline MJ: Histiocytes and histiocytosis. Blood 1994, 84: $2840-2853$
48. Bouwens L, Baekeland M, De Zanger R, Wisse E: Quantitation, tissue distribution and proliferation kinetics of Kupffer cells in normal rat liver. Hepatology 1986, 6:718-722

49. Klein A, Zhadkewich M, Margolick J, Winkelstein J, Bulkley G: Quantitative discrimination of hepatic reticuloendothelial clearance and phagocytic killing. J Leukoc Biol 1994, 55:248-252

50. Udagawa N, Takahashi N, Akatsu T, Tanaka H, Sasaki T, Nishihara T, Koga T, Martin TJ, Suda T: Origin of osteoclasts: mature monocytes and macrophages are capable of differentiating into osteoclasts under a suitable microenvironment prepared by bone marrow-derived stromal cells. Proc Natl Acad Sci U S A 1990, 87:7260-7264

51. Odegaard JI, Chawla A: Pleiotropic actions of insulin resistance and inflammation in metabolic homeostasis. Science 2013, 339: $172-177$

52. Rosen ED, Spiegelman BM: Adipocytes as regulators of energy balance and glucose homeostasis. Nature 2006, 444:847-853

53. Wynn TA, Chawla A, Pollard JW: Macrophage biology in development, homeostasis and disease. Nature 2013, 496:445-455

54. Decker T, Kiderlen AF, Lohmann-Matthes ML: Liver macrophages (Kupffer cells) as cytotoxic effector cells in extracellular and intracellular cytotoxicity. Infect Immun 1985, 50:358-364

55. Hiraiwa K, van Eeden SF: Contribution of lung macrophages to the inflammatory responses induced by exposure to air pollutants. Mediators Inflamm 2013, 2013:619523

56. Timmons BC, Fairhurst AM, Mahendroo MS: Temporal changes in myeloid cells in the cervix during pregnancy and parturition. J Immunol 2009, 182:2700-2707

57. Mantovani A, Sozzani S, Locati M, Allavena P, Sica A: Macrophage polarization: tumor-associated macrophages as a paradigm for polarized M2 mononuclear phagocytes. Trends Immunol 2002, 23: 549-555

58. Biswas SK, Gangi L, Paul S, Schioppa T, Saccani A, Sironi M, Bottazzi B, Doni A, Vincenzo B, Pasqualini F, Vago L, Nebuloni M, Mantovani A, Sica A: A distinct and unique transcriptional program expressed by tumor-associated macrophages (defective NF-kappaB and enhanced IRF-3/STAT1 activation). Blood 2006, 107:2112-2122

59. Karin M, Greten FR: NF-kappaB: linking inflammation and immunity to cancer development and progression. Nat Rev Immunol 2005, 5: 749-759

60. Biswas SK, Sica A, Lewis CE: Plasticity of macrophage function during tumor progression: regulation by distinct molecular mechanisms. J Immunol 2008, 180:2011-2017

61. Biswas SK, Mantovani A: Macrophage plasticity and interaction with lymphocyte subsets: cancer as a paradigm. Nat Immunol 2010, 11: 889-896

62. Paletta-Silva R, Meyer-Fernandes JR: Macrophage plasticity and polarization: cell signaling mechanisms and roles in immunity. Handbook of Macrophages. Edited by Takahashi R, Kai H. Hauppauge, NY, NovaScience Publishers, 2012, pp 147-174

63. Biswas SK, Chittezhath M, Shalova IN, Lim JY: Macrophage polarization and plasticity in health and disease. Immunol Res 2012, 53: $11-24$

64. Stout RD, Suttles J: T cell signaling of macrophage function in inflammatory disease. Front Biosci 1997, 2:197-206

65. Stout RD, Suttles J: Functional plasticity of macrophages: reversible adaptation to changing microenvironments. J Leukoc Biol 2004, 76: 509-513

66. Lech M, Grobmayr R, Weidenbusch M, Anders HJ: Tissues use resident dendritic cells and macrophages to maintain homeostasis and to regain homeostasis upon tissue injury: the immunoregulatory role of changing tissue environments. Mediators Inflamm 2012, 2012: 951390

67. Mantovani A, Sica A, Sozzani S, Allavena P, Vecchi A, Locati M: The chemokine system in diverse forms of macrophage activation and polarization. Trends Immunol 2004, 25:677-686

68. MacMicking J, Xie QW, Nathan C: Nitric oxide and macrophage function. Annu Rev Immunol 1997, 15:323-350 
69. Galván-Peña S, O’Neill LAJ: Metabolic reprograming in macrophage polarization. Front Immunol 2014, 5:1-6

70. Martin P, Leibovich SJ: Inflammatory cells during wound repair: the good, the bad and the ugly. Trends Cell Biol 2005, 15:599-607

71. Brancato SK, Albina JE: Wound macrophages as key regulators of repair: origin, phenotype, and function. Am J Pathol 2011, 178: $19-25$

72. Daley JM, Brancato SK, Thomay AA, Reichner JS, Albina JE: The phenotype of murine wound macrophages. J Leukoc Biol 2010, 87: $59-67$

73. Khanna S, Biswas S, Shang Y, Collard E, Azad A, Kauh C, Bhasker V, Gordillo GM, Sen CK, Roy S: Macrophage dysfunction impairs resolution of inflammation in the wounds of diabetic mice. PLoS One 2010, 5:e9539

74. Ganesh K, Das A, Dickerson R, Khanna S, Parinandi NL, Gordillo GM, Sen CK, Roy S: Prostaglandin E(2) induces oncostatin $\mathrm{M}$ expression in human chronic wound macrophages through Axl receptor tyrosine kinase pathway. J Immunol 2012, 189: 2563-2573

75. Murray PJ, Allen JE, Biswas SK, Fisher EA, Gilroy DW, Goerdt S, Gordon S, Hamilton JA, Ivashkiv LB, Lawrence T, Locati M, Mantovani A, Martinez FO, Mege JL, Mosser DM, Natoli G, Saeij JP, Schultze JL, Shirey KA, Sica A, Suttles J, Udalova I, van Ginderachter JA, Vogel SN, Wynn TA: Macrophage activation and polarization: nomenclature and experimental guidelines. Immunity 2014, 41:14-20

76. Porcheray F, Viaud S, Rimaniol AC, Leone C, Samah B, DereuddreBosquet N, Dormont D, Gras G: Macrophage activation switching: an asset for the resolution of inflammation. Clin Exp Immunol 2005, 142:481-489

77. Zheng XF, Hong YX, Feng GJ, Zhang GF, Rogers H, Lewis MA, Williams DW, Xia ZF, Song B, Wei XQ: Lipopolysaccharideinduced M2 to M1 macrophage transformation for IL-12p70 production is blocked by Candida albicans mediated up-regulation of EBI3 expression. PLoS One 2013, 8:e63967

78. Heusinkveld M, van der Burg SH: Identification and manipulation of tumor associated macrophages in human cancers. J Transl Med 2011, 9:216

79. Heusinkveld M, de Vos van Steenwijk PJ, Goedemans R, Ramwadhdoebe TH, Gorter A, Welters MJ, van Hall T, van der Burg SH: M2 macrophages induced by prostaglandin E2 and IL-6 from cervical carcinoma are switched to activated M1 macrophages by CD4+ Th1 cells. J Immunol 2011, 187:1157-1165

80. Rodriguez-Prados JC, Traves PG, Cuenca J, Rico D, Aragones J, Martin-Sanz P, Cascante M, Bosca L: Substrate fate in activated macrophages: a comparison between innate, classic, and alternative activation. J Immunol 2010, 185:605-614

81. Rehman J, Li J, Orschell CM, March KL: Peripheral blood "endothelial progenitor cells" are derived from monocyte/macrophages and secrete angiogenic growth factors. Circulation 2003, 107: $1164-1169$

82. Rohde E, Malischnik C, Thaler D, Maierhofer T, Linkesch W, Lanzer G, Guelly C, Strunk D: Blood monocytes mimic endothelial progenitor cells. Stem Cells 2006, 24:357-367

83. Lawrence T, Natoli G: Transcriptional regulation of macrophage polarization: enabling diversity with identity. Nat Rev Immunol 2011, $11: 750-761$

84. Grinberg S, Hasko G, Wu D, Leibovich SJ: Suppression of PLCbeta2 by endotoxin plays a role in the adenosine $\mathrm{A}(2 \mathrm{~A})$ receptor-mediated switch of macrophages from an inflammatory to an angiogenic phenotype. Am J Pathol 2009, 175:2439-2453

85. Rauh MJ, Ho V, Pereira C, Sham A, Sly LM, Lam V, Huxham L, Minchinton AI, Mui A, Krystal G: SHIP represses the generation of alternatively activated macrophages. Immunity 2005, 23: 361-374

86. Ruffell D, Mourkioti F, Gambardella A, Kirstetter P, Lopez RG, Rosenthal N, Nerlov C: A CREB-C/EBPbeta cascade induces M2 macrophage-specific gene expression and promotes muscle injury repair. Proc Natl Acad Sci U S A 2009, 106:17475-17480

87. Sag D, Carling D, Stout RD, Suttles J: Adenosine 5 '-monophosphate-activated protein kinase promotes macrophage polarization to an anti-inflammatory functional phenotype. J Immunol 2008, 181:8633-8641

88. Mounier R, Theret M, Arnold L, Cuvellier S, Bultot L, Goransson O, Sanz N, Ferry A, Sakamoto K, Foretz M, Viollet B, Chazaud B: AMPK alpha 1 regulates macrophage skewing at the time of resolution of inflammation during skeletal muscle regeneration. Cell Metab 2013, 18:251-264

89. Perdiguero E, Sousa-Victor P, Ruiz-Bonilla V, Jardi M, Caelles C, Serrano AL, Munoz-Canoves P: p38/MKP-1-regulated AKT coordinates macrophage transitions and resolution of inflammation during tissue repair. J Cell Biol 2011, 195:307-322

90. Arranz A, Doxaki C, Vergadi E, Martinez de la Torre Y, Vaporidi K, Lagoudaki ED, Ieronymaki E, Androulidaki A, Venihaki M, Margioris AN, Stathopoulos EN, Tsichlis PN, Tsatsanis C: Akt1 and Akt2 protein kinases differentially contribute to macrophage polarization. Proc Natl Acad Sci U S A 2012, 109:9517-9522

91. Correll PH, Iwama A, Tondat S, Mayrhofer G, Suda T, Bernstein A: Deregulated inflammatory response in mice lacking the STK/RON receptor tyrosine kinase. Genes Funct 1997, 1:69-83

92. Chaudhuri A: Regulation of macrophage polarization by RON receptor tyrosine kinase signaling. Front Immunol 2014, 5:546

93. Sen CK: Wound healing essentials: let there be oxygen. Wound Repair Regen 2009, 17:1-18

94. Krek A, Grun D, Poy MN, Wolf R, Rosenberg L, Epstein EJ, MacMenamin P, da Piedade I, Gunsalus KC, Stoffel M, Rajewsky N: Combinatorial microRNA target predictions. Nat Genet 2005, 37 : 495-500

95. Banerjee S, Xie N, Cui HC, Tan Z, Yang SZ, Icyuz M, Abraham E, Liu G: MicroRNA let-7c regulates macrophage polarization. J Immunol 2013, 190:6542-6549

96. Maitra U, Gan L, Chang S, Li LW: Low-dose endotoxin induces inflammation by selectively removing nuclear receptors and activating CCAAT/enhancer-binding protein delta. J Immunol 2011, 186: $4467-4473$

97. Ponomarev ED, Veremeyko T, Barteneva N, Krichevsky AM, Weiner HL: MicroRNA-124 promotes microglia quiescence and suppresses EAE by deactivating macrophages via the C/EBP-alphaPU.1 pathway. Nat Med 2011, 17:64-70

98. Zhuang GQ, Meng C, Guo X, Cheruku PS, Shi L, Xu H, Li HG, Wang G, Evans AR, Safe S, Wu CD, Zhou BY: A novel regulator of macrophage activation miR-223 in obesity-associated adipose tissue inflammation. Circulation 2012, 125:2892-2903

99. Reddy MA, Chen Z, Park JT, Wang M, Lanting L, Zhang Q, Bhatt K, Leung A, Wu X, Putta S, Saetrom P, Devaraj S, Natarajan R: Regulation of inflammatory phenotype in macrophages by a diabetes-induced long non-coding RNA. Diabetes 2014, 63 : 4249-4261

100. Li Z, Chao TC, Chang KY, Lin N, Patil VS, Shimizu C, Head SR, Burns JC, Rana TM: The long noncoding RNA THRIL regulates TNFalpha expression through its interaction with hnRNPL. Proc Natl Acad Sci U S A 2014, 111:1002-1007

101. Hirose K, Iwabuchi K, Shimada K, Kiyanagi T, Iwahara C, Nakayama H, Daida H: Different responses to oxidized low-density lipoproteins in human polarized macrophages. Lipids Health Dis 2011, 10:1

102. Samuelsson B, Dahlen SE, Lindgren JA, Rouzer CA, Serhan CN: Leukotrienes and lipoxins: structures, biosynthesis, and biological effects. Science 1987, 237:1171-1176

103. Serhan CN: Resolution phase of inflammation: novel endogenous anti-inflammatory and proresolving lipid mediators and pathways. Annu Rev Immunol 2007, 25:101-137

104. Hong S, Porter TF, Lu Y, Oh SF, Pillai PS, Serhan CN: Resolvin E1 metabolome in local inactivation during inflammation-resolution. J Immunol 2008, 180:3512-3519 
105. Dalli J, Serhan CN: Specific lipid mediator signatures of human phagocytes: microparticles stimulate macrophage efferocytosis and pro-resolving mediators. Blood 2012, 120:E60-E72

106. Yan D, Wang X, Li D, Qu Z, Ruan Q: Macrophages overexpressing VEGF, transdifferentiate into endothelial-like cells in vitro and in vivo. Biotechnol Lett 2011, 33:1751-1758

107. Kim SJ, Kim JS, Papadopoulos J, Wook Kim S, Maya M, Zhang F, He J, Fan D, Langley R, Fidler IJ: Circulating monocytes expressing CD31: implications for acute and chronic angiogenesis. Am J Pathol 2009, 174:1972-1980

108. Maruyama K, Ii M, Cursiefen C, Jackson DG, Keino H, Tomita M, Van Rooijen N, Takenaka H, D’Amore PA, Stein-Streilein J, Losordo DW, Streilein JW: Inflammation-induced lymphangiogenesis in the cornea arises from CD11b-positive macrophages. J Clin Invest 2005, 115: $2363-2372$

109. Sharifi BG, Zeng Z, Wang L, Song L, Chen H, Qin M, SierraHonigmann MR, Wachsmann-Hogiu S, Shah PK: Pleiotrophin induces transdifferentiation of monocytes into functional endothelial cells. Arterioscler Thromb Vasc Biol 2006, 26:1273-1280
110. Bronte V, Serafini P, Apolloni E, Zanovello P: Tumor-induced immune dysfunctions caused by myeloid suppressor cells. J Immunother 2001, 24:431-446

111. Gabrilovich DI, Velders MP, Sotomayor EM, Kast WM: Mechanism of immune dysfunction in cancer mediated by immature Gr-1+ myeloid cells. J Immunol 2001, 166:5398-5406

112. Watkins SK, Egilmez NK, Suttles J, Stout RD: IL-12 rapidly alters the functional profile of tumor-associated and tumorinfiltrating macrophages in vitro and in vivo. J Immunol 2007, 178:1357-1362

113. Senju S, Haruta M, Matsumura K, Matsunaga Y, Fukushima S, Ikeda T, Takamatsu K, Irie A, Nishimura Y: Generation of dendritic cells and macrophages from human induced pluripotent stem cells aiming at cell therapy. Gene Ther 2011, 18:874-883

114. Jiang Y, Cowley SA, Siler U, Melguizo D, Tilgner K, Browne C, Dewilton A, Przyborski S, Saretzki G, James WS, Seger RA, Reichenbach J, Lako M, Armstrong L: Derivation and functional analysis of patient-specific induced pluripotent stem cells as an in vitro model of chronic granulomatous disease. Stem Cells 2012, 30:599-611 